The Canadian Journal of Higher Education, Vol. XXV-2, 1995

La revue canadienne d'enseignement supérieur, Vol. XXV-2, 1995

\title{
Retaining women students in science involves more than course selection.
}

\section{E.L. DONALDSON \& E.A. DIXON*}

\section{Abstract}

Difficulties in retaining women students in undergraduate science courses are well-known, but reasons for the attrition are less well understood. Data from a survey of first-year chemistry students suggests that gender differences with regard to pre-entry attributes and the transition to the university, the oncampus experience, perceived competencies in academic skills and science literacy, and undergraduate transitions to work may contribute to decisions to leave science, but not necessarily to leave the university. In one university, short-term intervention strategies such as curricula changes, the addition of female faculty role models, the introduction of promotional activities, and the formation of peer support groups are increasing retention. Follow-up data from Phase Two of this study should provide other indicators, but differences in course selection between young women and men enrolled in university appear to be influenced by their values, thus contributing to differing career choices.

\section{Résumé}

Les difficultés à garder des étudiantes dans les cours de sciences sont bien connues mais les raisons pour le décrochage sont moins comprises. Les données d'une étude sur des étudiants dans un cours de première année de chimie suggère que les différences de genre en ce qui concerne leurs qualités avant l'inscription et la transition à l'université, l'expérience d'apprentissage postsecondaire, les capacités perçues dans les habiletés académiques,

\footnotetext{
* University of Calgary
} 
l'alphabétisme scientifique, et la transition de l'école secondaire à l'université pourraient contribuer à la décision de laisser tomber les sciences, mais pas nécessairement l'université. Dans une université, les stratégies d'intervention à court terme telles que la commission de pilotage pour les étudiants en première année, qui fait des changements au programme d'études, les modèles de rôles des femmes de la faculté, les activités promotionnelles et le soutien des groupes de pairs, semble augmenter l'inscription. Les données issues du suivi de la deuxième phase de l'étude devrait fournir d'autres indices, Mais les différences dans le choix des cours entre les jeunes femmes et les jeunes hommes qui s'inscrivent à l'université semblent influencées par les valeurs, lesquelles contribuent à différencier les choix de carrière.

Although a gender balance is now characteristic of undergraduate registration at most universities and in large first-year chemistry courses, women students withdraw from science programs more quickly than do male students. However, the drift of talented youth from science careers is a serious concern regardless of gender. Students do not always make course selections or career choices based upon an understanding of the challenges or upon long-term objectives. According to Gilbert and Pomfret (1991) and Tinto (1987), the departure of students from postsecondary education is influenced by pre-entry attributes, initial goals and commitments, formal and informal institutional experiences, emergent goals and commitments, and educational outcomes. In addition to structural influences within the educational systems, students may be influenced by perceptions of their abilities and by part-time work and peer relationships, especially during transition phases to and from the university (Donaldson, 1990). Given the importance of science and technology to our rapidly changing society, the retention of student achievers within disciplines such as chemistry is an important issue for faculty and administrators, as well as for the general public.

In academic disciplines where women are in a minority situation, the intellectual and social climate has been called "chilly" for young women, thus reducing a sustained interest in career-related fields (Williams, 1990; University of Western Ontario, 1991). When women, who value discussion because it builds relationships in addition to constructing meaning, study science in isolation with an emphasis upon technique unrelated to application, they may well decide they are too "dumb" to understand the course content and enroll in courses where they feel more included, interested, and important. But society needs more scientists who enjoy talking about their work, its standards, and its relevance. Thus, the loss of female students may well be a "hemorrhage" of talent that our culture cannot afford (Tobais, 1990). 
When relationship values that influence women are combined with a culture of science which is chilly, some of the reasons for women's selection of courses at university become more obvious (Gilligan, Lyons, \& Hanmer, 1990; Williams, 1990). If young women students in particular are affected by relationships (e.g., their friends are not in science), by part-time work (e.g., their earning power is not substantial and their consumer lifestyles are expensive), and grades (e.g., high marks contribute to high self-esteem and low marks to low esteem), then the reasons for the drift from science may have less to do with the culture of science and more to do with North American values than has been suspected

In this paper the focus is upon significant gender differences between young women and men that may be contributing reasons to why these students might be retained at university, but not in science. Differences in student perceptions of their personal attributes, the postsecondary learning environment with regard to chemistry, the first-year experience, and intentions with regard to anticipated university-to-career transitions patterns are reported. Quantitative and qualitative data from Phase One of a three-year study are presented, and proactive strategies that have been implemented are summarized.

\section{Conceptual Frameworks in the Literature}

Tinto's model of institutional departure has been widely used to provide a framework for discussions about issues associated with the retention and attrition of university students, particularly among first-year students (Tinto, 1987; Gilbert \& Pomfret, 1991; Chenard, 1988). However, while Tinto's work has helped to articulate a theory of institutional departure and to focus attention upon the need for appropriate policy development, there is little discussion of gender differentiations among students and off-campus influences such as parttime work are addressed but briefly.

Gilbert and Pomfret (1991) adapted this model at a residential university when identifying gender patterns among renewal rates for students who had received Canada Scholarships in science. They concluded that "fundamental gender patterns in values, encouragements, and perceptions of self and science" (pp. ii-iii) affect recruitment, persistence, experience, and decisions to depart. They suggest that if "educational climates" within the sciences more closely reflected this value system then more talented women might be retained in science. The Guelph model they developed was refined for a survey of first-year chemistry students' perceptions and intentions. That is, the institutional model provided a framework to ask questions of a large undergraduate class so that 
data on socioeconomic background variables, formal and informal institutional influences, and emergent goals and commitments could be utilized by chemistry faculty when planning curricula changes.

Tobias' study (1990) of American nonscience graduate student perceptions of how science is taught, and the resultant culture of science that alienates many women, also suggests that concepts of science competency may be genderbiased. Tobias argues that the talent pool is depleted because the science community tends to reproduce younger versions of "self-motivated, extraordinarily self-confident, virtually teacher-and curriculum-proof, indifferent to material outcomes, single-minded and single-track" people (1990, p. 11).

Concerns about competitiveness, science literacy, and development of talent among an increasingly small number of youth in the population are echoed by Science Culture Canada and other federal initiatives designed to facilitate a more positive science-oriented culture. Einsiedel's (1990) gender-balanced study of science literacy among adults indicated that Canadians who had completed high school science and university science courses were more knowledgeable about the importance of science to society, but many female respondents scored more poorly than males. Einsiedel's sample was 2000 adults, not necessarily university educated. However, $51 \%$ of the female respondents scored low on the scientific literacy index (at the same low level males scored $28 \%$ ) but only $9.8 \%$ of females scored high while $29 \%$ of the males scored high (1990, p. 22). This index included a definition of a scientific study and answers to questions about the general environment and health. Questions from Einsiedel's study were included in the questionnaire developed for the chemistry study reported here.

Finally, transitions to and from university are known to be difficult passages for many students because they are interim periods of adjustment which are psychologically stressful. The transition from university to career path involves a set of skill competencies that are often meta-curricular such as time management (Evers, Rush, \& Krmpotic, 1991). The extent to which gender influences this transition may be less obvious at a skills development level than it is in personal decision-making (Mandell \& Crysdale, 1993). Cooperative education is used more extensively by women than apprenticeship as a link between education and employment; part-time work is also an important link (Donaldson, 1992).

Although the transition period is a "scheduled status passage," the research that identifies issues and pressures which affect students when they make decisions during the first-year of university, thus profoundly influencing their subsequent careers, is a relatively new field of study. Research about the influence of 
the teaching environment upon these students is even more sparce. Encouragingly, since the commencement of the project discussed in this paper, several articles pertinent to the Canadian postsecondary learning environment have been published (Williams, 1990; Corman, Barr \& Caputo, 1992; Gomme, Hall \& Murphy, 1993; McKeown, MacDonnell \& Bowman, 1993; Etcheverry, Clifton \& Roberts, 1993). These authors argue for curricula and policies that reflect a commitment to equity issues and reflect student perspectives. Williams notes that the few studies on sex-biased classroom practices concur that female faculty are important role models, but there is a paucity of research about the impact of gender bias on women in nontraditional majors. Reasons for undergraduate attrition in North America, whether from classroom attendance, from programs of study, or from university itself may vary somewhat between the United States and Canada. Canadian institutions are usually commuter institutions where relationships between classroom experiences and attrition are particularly important (Corman et al., 1992). According to Etcheverry et al. (1993) relationships between studying, paid employment, and GPA are influenced more by the number of credit hours, motivation, and self-concept of ability than by background variables. However, the lack of research regarding student perspectives about university life and academia leave many gaps in the current profile (Gomme et al.; and McKeown et al., 1993). In a recent video produced by the University of Western Ontario (1991) it is suggested that a combination of stereotyping, exclusion, isolation, and type of evaluation add up to "subtle discriminating practices" that create a working environment which "prohibits" women from "achieving their full potential in academia." Thus, the complexities of the issues are beginning to be understood, but much more work needs to be done. During the past 20 years the university student profile has changed, reflecting general demographics. The marketplace has also shifted, creating sunset and sunrise industries and technologies. However, much as universities have adjusted, it is apparent that more restructuring must occur. Thus, an understanding of student lifestyles and perspectives contributes to the development of effective policies, especially during a period of downsizing. The study described here makes a contribution to this aspect of the issue.

\section{Method}

First-year chemistry students at a commuter campus in Western Canada were asked to participate in a survey designed to obtain student intentions and perceptions of the university experience. This course, the sixth largest at the university, has a relatively equitable gender balance in first-year enrollment 
compared with biology and physics. Also, proactive university-wide orientation strategies together with a limited growth policy stimulated the Department of Chemistry, along with many others in North American universities, to review its approach to teaching the undergraduate entry-level course. In 1990, although enrollment in the first-year course was 899 students, only 11 students graduated with a Bachelor's degree in chemistry, only 7 graduate degrees were awarded, and not all of the cooperative education positions for undergraduate chemistry students were filled. This high attrition rate was a concern to the Department of Chemistry and was one of the reasons for the study, initiated in 1991.

Data reported in this paper were obtained during Phase One (1991) of a two-stage study. Phase Two (1993) was initiated after an interim year; analyses of these data are in progress and are not reported here. The four objectives of the research project (1991-1994) are (a) to compare student profiles of two cohorts of chemistry students, (b) to identify student understandings of science culture and science literacy, (c) to track undergraduate students as they completed their first two years of university, and (d) to integrate the research results with planned curriculum change within the discipline and with first-year experience initiatives at the university. The research design of the project includes generation of both quantitative and qualitative data so that a "triangulated" understanding of the issues could be obtained using questionnaires, taped smallgroup discussions, and on-site visits to classrooms and laboratories. As well, achievement and registration data have been consulted.

During analysis of the Phase One data, significant gender differences were noted among the quantitative data; comments from the student group sessions and on-site observations helped develop an understanding of how university experiences of women students apparently differ from those of male students. Of the data, only results pertinent to the purpose of this paper are discussed here; that is, the discussion is limited to an identification of some of the nonacademic reasons that contribute to the drift of women students from science and of some strategies that appear to retain them effectively.

\section{Results}

As Table 1 indicates, enrollment in the course is high, withdrawal and failure rates are low, and participation in the study reflected the gender distribution of the total enrollment. A questionnaire, administered in class after the date students could drop the course without penalty or mailed to students who had withdrawn from the course, produced a $60 \%$ response rate; excluded from this paper are data from the nine questionnaires in which gender was not reported. While 
Table 1

A Descriptive Profile of First-Year Chemistry Student Performances"

Enrollment

$\begin{array}{ll}\text { total } & 962 \\ \text { female } & 415 \\ \text { male } & 547\end{array}$

Chi Square $\left(\mathrm{X}^{2}\right)$

Withdrawals

$\begin{array}{ll}\text { total } & 66 \\ \text { female } & 35 \\ \text { male } & 31\end{array}$

Failures

total

female 36

male 28

Final grade point average

$\begin{array}{ll}\text { total } & 2.50 \\ \text { female } & 2.55 \\ \text { male } & 2.46\end{array}$

\section{Participation in study}

$\begin{array}{lc}\text { total (\%) } & 574(60 \%) \\ \text { female } & 291 \\ \text { male } & 274 \\ \text { gender not stated } & 9^{*}\end{array}$

Note: None of these statistics were significant with regard to gender differences,

* Data from these students have been excluded from this paper.

** Data obtained from Office of Institutional Analysis, University of Calgary. 
results may be biased because of absenteeism, subsequent analyses of the final grades indicate that the sample comprised approximately two-thirds of the higher achievers and about half of the low achieving students. In addition to the questionnaire, follow-up videotaped small group discussions (34 students participated: 20 females, 14 males) confirmed and deepened an interpretation of the questionnaire themes and raised new questions.

Data from more than 190 questions asked during Phase One of the study were analyzed using descriptive and multivariate techniques (Chi-square, Pearson product moment correlations, $\mathrm{p}=<.05$ ). Most questions were 5 point, Likert-scale; however, in some questions, such as part-time work, the students were asked to select one of five options and a few of the closed-ended questions offered an option of "other" with a request for an explanation. Fourteen questions were open-ended; as was expected the numbers of responses dropped but responses were sufficiently complete that classification scales could be developed for coding purposes or the phrasing could be interpreted and quoted.

The questionnaire was organized into five thematic areas developed from the Gilbert and Pomfret (1991) adaptation of the Tinto model (1987), Einsiedel's (1990) science literacy project, and Donaldson's study (1992) of student transitions. The five themes framing the scope of the questions included: pre-entry attributes of the students and the transition to university, the postsecondary learning environment, perceived competencies in academic skills, science literacy, and school-work transition patterns. Together, they provide a comprehensive profile about the university experience of undergraduate science students and, in some important aspects, gender makes a difference. The results reported here are grouped according to significant gender differences in pre-entry attributes, on-campus experiences, perceived competencies in academic skills, and general knowledge of science, and linkages between education and work. Preceding these results is a summary demographic profile.

A demographic profile of the students

The majority of the respondents were full time, first-year students $(80.5 \%)$, and a few were full-time second year students $(9.1 \%)$. Only 27 students indicated they were part-time first semester $(2.1 \%)$ or second year $(2.6 \%)$. These students were primarily English-speaking (78\%), Canadian by birth $(76.8 \%$ ) or by immigration (17.4\%). They lived at home with their parents (72.8\%), off campus with friends $(15.3 \%)$ or alone $(5.6 \%)$, and a few lived in residence $(5.7 \%)$. Most described themselves as middle class (50.3\%) or upper middle class $(25.6 \%)$. Few of these students $(5 \%)$ previously had attended other postsecondary institutions. Most transferred directly from high school to university $(70.7 \%)$, the majority being single $(92.7 \%)$ without children of their own $(97.8 \%)$. The 
sample also mirrored first-year cohort demographics on campus and the enrollment in the class

Parental influence is known to affect university achievement, contributing to the formation of a career and lifestyle. Not surprisingly, these young people generally had the support of both mother and father in a family home $(88.7 \%)$ and the parental educational levels were fairly high. More than $61 \%$ of the fathers and $57 \%$ of the mothers had completed tertiary education. Nevertheless, student estimates of sources of income were diverse and estimates of personal income tended to be low (74\% estimated they earned less than $\$ 5,000$ per annum). Major sources of income were family $(21.8 \%)$, government assistance $(15.3 \%)$, part-time work (19.5\%), scholarship (28.4\%), and summer savings (12.7\%).

Although these students reported being on campus five days $(65.7 \%)$ or more $(25.3 \%)$ per week, they did not mix well, demonstrating an absence of social integration that Tinto (1987) claims results in underachievement and dropouts. Many travelled to campus alone in an automobile (27.2\%) or by rapid transit and bus (41\%); few used car pools (16\%). While most either shared a meal with friends or occasionally ate alone, $(73 \%), 27 \%$ were more solitary, usually eating lunch alone $(7.3 \%)$, skipping the meal $(9.4 \%)$ or eating off campus $(10.3 \%)$. A minority of students were active in off-campus groups (39\%), and some were active in on-campus groups (35\%). Although half of the students reported participating in first year orientation activities (52.8\%), at the end of their first semester, only a few students reported that they had formed friendships with classmates (12.2\%) or made new social acquaintances $(20.9 \%)$; a few reported they didn't know anyone (3.8\%).

\section{Pre-entry attributes of the students}

Students were asked 30 questions about their background that included the language first spoken in childhood, parental education, major sources of income for the semester, activities in off-campus groups, type of transportation used to get to campus, important influences in selecting an undergraduate major, part-time work, satisfaction and happiness, and the difficulty of the transition to university.

As Table 2 indicates gender differences were statistically significant in five pre-entry attributes. The influence of siblings, high school teachers and counsellors, more so than mother or father, is important to young women as they enter university. Also high school academic achievements and expectations of continued good marks were more important to young women. Finally, while both female and male undergraduates think it important to be self-sufficient, at this early stage of their postsecondary education more young women than young men were concerned about being self-sufficient. These findings are 
Table 2

Differences between Women and Men in Pre-entry Attributes $(n=565)$

\begin{tabular}{|c|c|c|c|c|c|}
\hline \multirow[b]{3}{*}{ Pre-entry Attributes } & \multicolumn{4}{|c|}{ Gender } & \multirow[b]{3}{*}{$X^{2}$} \\
\hline & \multicolumn{2}{|c|}{ Female } & \multicolumn{2}{|c|}{ Male } & \\
\hline & $\mathrm{n}$ & $\%$ & $\mathrm{n}$ & $\%$ & \\
\hline 1. Influence of brothers and sisters* & 48 & 64 & 27 & 36 & 10.58 \\
\hline $\begin{array}{l}\text { 2. Influence of high school teachers } \\
\text { and counsellors* }\end{array}$ & 126 & 61 & 80 & 39 & 11.70 \\
\hline $\begin{array}{l}\text { 3. High school interests and achievement } \\
\text { in subject* }\end{array}$ & 173 & 58 & 125 & 42 & 12.19 \\
\hline 4. Expectation of good marks * & 178 & 58 & 129 & 42 & 13.91 \\
\hline 5. Desire to be self-sufficient $* *$ & 162 & 56 & 123 & 44 & 21.42 \\
\hline
\end{tabular}

Note: All non-significant findings have been omitted.

$* \mathrm{p}<.05 . \quad * * \mathrm{p}<.01$.

consistent with those reported in the Gilbert and Pomfret study (1991) in that the findings from both studies suggest that women, more than men, are influenced by relationships and that women, more than men, incorporate academic achievement as a component of their self-esteem.

\section{On-Campus Experiences}

Students were asked questions regarding the postsecondary learning environment that probed their approaches to learning chemistry, their perceptions of first year, and their use of university services. Responses in which gender appears to be significant are listed in Table 3.

Questionnaire respondents were asked 25 questions about the first-year chemistry class and 58 questions about the first-year experience of being on campus. Questions regarding the chemistry course asked about study habits, the learning environment, and course management. The questions about the first year experience probed student reasons for attending university, their reasons for enrolling at this university, what were their major worries, and what services they used. Statistically significant differences appeared in four questions regarding the chemistry course, in six areas of the first-year experience, and in seven areas of university services usage.

With regard to gender differences and the pedagogy of the chemistry course, as Table 3 Part A, indicates, women most differed from men students 
Table 3

Differences Between Women and Men With Regard to On-Campus Experiences $(n=565)$

\begin{tabular}{lllllll}
\hline & \multicolumn{3}{c}{ Gender } & & \\
University Experiences & $\mathrm{n}$ & $\%$ & $\mathrm{n}$ & $\%$ & $\mathrm{X}^{2}$ \\
\hline
\end{tabular}

Part A: Women's Studying Patterns / Preferred Changes (Chemistry)

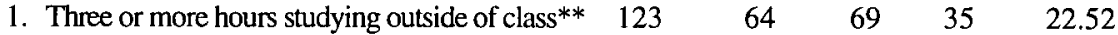

3. Preferred change in labs*

$11 \quad 31 \quad 25 \quad 69$

4. Preferred evaluation in labs*

$25 \quad 64 \quad 14 \quad 36$

PART B: Women's FIRST-Year PERCEPTIONS

1. More influenced by high school mentors re: university*

$\begin{array}{llll}47 & 64 & 26 & 36\end{array}$

11.41

2. More neutral re: reputation of the university* 116

3. More participation in orientation activities ** 71

4. Made more new acquaintances on-campus * 104

$\begin{array}{lll}60 & 78 & 40\end{array}$

5. Worried more about ability to do university level work**

6. More positive about professors and teaching assistants**

PART C: WOMEN's USE OF UNIVERSITY SERVICES

$\begin{array}{lllllll}\text { 1. Used Peer Support Centre more ** } & 24 & 75 & 8 & 25 & 7.49\end{array}$

2. Used Student Resource Centre more * $\quad \begin{array}{llllll} & 104 & 59 & 73 & 41 & 5.96\end{array}$

3. Used University Health Services more* $\quad \begin{array}{llllll}66 & 60 & 44 & 40 & 3.94\end{array}$

4. Visited the used book store more ** $\quad \begin{array}{llllll}* * & 173 & 56 & 136 & 44 & 6.53\end{array}$

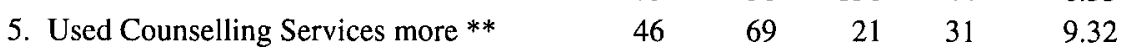

6. Used Campus Recreation less ** $\quad \begin{array}{llllll}* * & 155 & 46 & 181 & 54 & 8.28\end{array}$

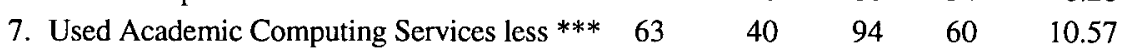

Note: All non-significant findings have been omitted.

$$
{ }^{*} \mathrm{p}<.05 \quad * * \mathrm{p}<.01 \quad * * * \mathrm{p}<.001
$$


with regard to the time they spent studying chemistry, preferred learning resources, and environment and evaluation. Female students spent significantly more time studying outside of class, an estimated three or more hours per week. Students also differed with regard to the learning resources they preferred. While most of the students preferred a combination of resources or the textbook, women liked audio-visual materials less than the men. Most students indicated that the one change they would most like in the course would be more small-group discussions; after that choice, they would like more in-class demonstrations. However, more women preferred changes in the laboratories than did men. With regard to evaluation, the majority of students accepted the inevitability of multiple choice examinations with men favouring this method, but more women than men preferred laboratory evaluations.

In summary, women students spent considerably more time studying than did the men. More women preferred the laboratory manual as a learning resource and the laboratory experiment as an evaluation, while more men preferred audio-visual aids and multiple choice evaluations. If changes were to be made, more women would prefer more interactive laboratory experiments.

First year female and male students also experienced the university milieu in significantly different ways. In six aspects of campus life, differences emerged in reasons for selecting the university and in factors that were worrying to them. As Table 3 Part B indicates, these first-year women were more influenced by high school mentors such as teachers and counsellors than were their male counterparts and were more neutral about the overall reputation of the university. They participated more in orientation activities and made more new on-campus acquaintances. Although they worried considerably more than men about their ability to do university level work, they also were more positive about the professors and teaching assistants.

As Table 3 Part $\mathrm{C}$ indicates, these influences and concerns were manifested in the different university services utilized by undergraduate women. They frequented the peer support and student resources centre, health services, and counselling services more than did men; they also visited the used bookstore more. However, they utilized the campus recreation facilities and the academic computing services less.

In summary, as Gilbert and Pomfret's (1991) results also indicated, women students more than men tend to rely upon school advisors and to be more concerned about their abilities to achieve within an academic environment. Perhaps the increased use of student support resources reflects these self-esteem needs as well as concerns about finances. If they visit the recreational facilities less than men, perhaps they are less physically fit; if they use the computing 
services less frequently, perhaps they are not as technologically fluent as men. The effect of lowered self-esteem upon women's career development is wellestablished; however, the mechanisms by which women build self-esteem are not so well understood (Streit \& Tanquay, 1994). If attitudes of personal and professional competence are developed by participation in sports and a predisposition for technology in men, is it reasonable to assume similar participatory rates in facility usage would do the same for women?

\section{Perceived Competencies in Academic Skills and General Knowledge of Science}

Student perceptions of their ability to achieve often affect their decisions about what courses to take or what career path to develop. Gilbert \& Pomfret's (1991) research suggested that significant gender differences emerged with regard to student rankings of competencies in such areas as thinking and reasoning, problem-solving, quantitative and mathematical skills, decision-making, planning and organizing activities, communication, time management, and independence. The ability to visualize is of increasing importance to scientists, so this skill area was added to make a list of nine competency areas.

In both studies, students were asked to rate their level of competence in each category on a 5-point scale, ranging from extremely high to very low competence, and the results are similar. In the study reported here, gender-correlated student responses were statistically significant in five of nine areas. Female perceptions of their competencies were lower than males in thinking and reasoning $(\mathrm{p}=<.001)$ and problem-solving $(\mathrm{p}=<.0006)$. Females also rated themselves lower than males with regard to visualization skills $(p=<.03)$. Conversely, females rated themselves higher than males in planning and organizing $(\mathrm{p}=<.00001)$ and in time management $(\mathrm{p}=<.02)$.

Einsiedel's (1990) telephone survey of Canadians over the age of 18 was designed to assess attitudes toward science and technology, to assess levels of knowledge about Canadian science, and to describe science literacy among adult Canadians. Fifteen questions in this study of first-year year science students replicated the Einsiedel (1990) science literacy research, although the responses were written while the adult data were generated during a telephone interview. As would be expected, the student answers to questions about general scientific knowledge were higher than that of the adult population; nevertheless, the responses from both populations were sometimes frighteningly poor. Nearly two-thirds of the respondents in Einsiedel's study were unable to name a single achievement in Canadian science or to name a Canadian scientist. Among the first-year university science students slightly more than one-third $(35 \%)$ could not name either an achievement or a scientist, and only $12 \%$ 
attempted to name three. With regard to frequency of responses, there were no gender differences. In response to an open-ended question about what is a "scientific study," $24 \%$ of the students did not respond, and only $36 \%$ made reference to a hypothesis or methodology in their written answers.

In closed-ended questions about general knowledge of science, six of 13 questions produced statistically significant gender differentiated responses. Of the 72 students who did not know whether radioactive milk could be made safe by boiling it, $63 \%$ were women; of the three students who thought that it could, all were men. Of the 61 students who didn't know whether lasers work by focusing sound waves (the only content question in the section included in the course curriculum), $75 \%$ were female; of the 24 students who answered incorrectly, $71 \%$ were female. Both the students who indicated they didn't know whether the sun went around the earth or vice versa were female; of the other 20 students who responded incorrectly, $80 \%$ were female. Of 15 students who stated that they didn't know the cause of acid rain was coal-fired power plants, $80 \%$ were female; of 92 other students who selected incorrect responses such as aerosol sprays, nuclear power plants, and chemical warfare byproducts, female incorrect responses ranged from $60 \%-78 \%$. When asked whether they thought a cure for common forms of cancer might be achieved or a human might be landed on Mars in the next 25 years or so, males and females differed significantly. More females than males thought it unlikely a cure for cancer would be discovered ( $p=<.04)$; females, more than males, thought it unlikely that a landing on Mars would occur or they didn't respond $(p=<.0018)$.

In summary, while the undergraduate science students are more science literate than the general public, their knowledge about Canadian achievers and achievements is poor. This deficit raises concerns about appropriate cultural role models and their understanding of the role of science in our society.

\section{Linkages between education and work}

Although the majority of students in this study were in their first semester at university, just making the transition from high school, several questions probed their thinking about their future after departure from the campus. These themes included nine questions about school-work linkages and two sets of six questions about part-time work. Significant differences emerged in four areas as indicated in Table 4 . These women, more so than men students, realistically anticipated more difficulties in combining family responsibilities with a career. Much more than men students, they also thought that previous part-time work and volunteer experience might be useful when making the transition from university into adult life. They also anticipated that cooperative education might 
Table 4

Gender Differences in Linkages Between Education and Work ( $n=565)$

\begin{tabular}{|c|c|c|c|c|c|}
\hline \multirow[b]{3}{*}{ Linkage to Work } & \multicolumn{4}{|c|}{ Gender } & \multirow[b]{3}{*}{$\mathrm{X}^{2}$} \\
\hline & \multicolumn{2}{|c|}{ Female } & \multicolumn{2}{|c|}{ Male } & \\
\hline & $\mathrm{n}$ & $\%$ & $\mathrm{n}$ & $\%$ & \\
\hline $\begin{array}{l}\text { 1. Anticipate more difficulties combining } \\
\text { family and career responsibilities* }\end{array}$ & 112 & 60 & 77 & 41 & 10.38 \\
\hline 2. Useful previous part-time employment** & 49 & 60 & 33 & 40 & 13.99 \\
\hline 3. Useful cooperative education program $* * *$ & 91 & 60 & 61 & 40 & 18.69 \\
\hline 4. Useful volunteer experience**** & 125 & 64 & 71 & 36 & 42.04 \\
\hline
\end{tabular}

Note: All non-significant findings have been omitted.

$* \mathrm{p}<.05 \quad * * \mathrm{p}<.01 \quad * * * \mathrm{p}<.001 \quad * * * * \mathrm{p}<.0001$

ease transition challenges more. Much more research needs to be done on gender differences that emerge when students attempt to link education-work-family opportunities and responsibilities as little is understood about the female mid-life cycle.

With regard to current part-time work, 277 students (48\% of the total respondents) indicated their wages. While $60 \%$ of those who responded to this question earned less than $\$ 100$ per week (29\% of the female students and $31 \%$ of the males), more females than males earned between $\$ 100$ and $\$ 250$ per week (19\%) and more males than females earned between $\$ 250-\$ 300$ per week $(4 \%)$. However, a few more females than males earned more than $\$ 300$ per week $(1 \%)$, probably because they were older, reentry students.

One year after participating in this study, 888 (of the original 962 students who had enrolled) returned for the Fall semester. The majority of the students were still in General Studies (the usual two-year entry route for students at this university) but for the first time more women students (104) than men (94) enrolled in the Faculty of Science. With regard to the $60 \%$ of the total enrollment who comprised the study sample, as Table 5 indicates, the number of women being retained in science was slightly higher than those of men, and the persistence of students in science was encouraging. 
Table 5

Student Registration at Time of Study and One Year Later $\left(n=574^{1}\right)$

\begin{tabular}{lrrrr}
\hline Faculty & \multicolumn{2}{c}{1991} & \multicolumn{2}{c}{1992} \\
& F & M & F & M \\
\hline General Studies & 270 & 248 & 134 & 117 \\
Science & 8 & 12 & 72 & 70 \\
Education & 1 & 1 & 1 & 2 \\
Engineering & 0 & 0 & 4 & 5 \\
Social Sciences & 1 & 2 & 13 & 6 \\
Humanities & 1 & 2 & 2 & 0 \\
Nursing & 0 & 0 & 2 & 0 \\
Physical Ed. & 8 & 6 & 7 & 4 \\
Management & 0 & 0 & 1 & 1 \\
Fine Arts & 0 & 1 & 1 & 2 \\
University withdrawal & 0 & 0 & 54 & 67 \\
Unclassified & 2 & 2 & & \\
Total & $\mathbf{2 9 1}$ & $\mathbf{2 7 4}$ & $\mathbf{2 9 1}$ & $\mathbf{2 7 4}$ \\
\cline { 1 - 2 } * Data obtained from Office of Institutional Analysis, University of Calgary. & \\
1 Includes 565 of 574 students; 9 students gender not reported. & \\
\hline
\end{tabular}

\section{Discussion}

The data presented in this paper develop a student profile with regard to five aspects of undergraduate student life. In this discussion, the interpretation of results has been amplified by the follow-up videotaped group sessions with a small self-selecting sample of the questionnaire respondents, visits to the laboratory, and discussions with chemistry faculty. Significant differences between young women and men indicate that the university experience is not identical and that the differences contribute to talent development and future aspirations but not necessarily to attrition from university itself. Since withdrawals and failures are low, women students appear to be selecting courses differently because of pre-entry attributes and influences, the learning environment, use of university resources, varied behaviours during transitional periods, and, perhaps 
most important, perceptions about their abilities to succeed within the academic environment although their final achievement scores are similar to those attained by male counterparts.

With regard to pre-entry student attributes, of interest is the "desire to be self-sufficient" in young women as they become independent adult citizens. Yet they are more influenced by siblings, counsellors, and academic achievement than are young men. One interpretation of this result may be that women are less certain than men with regard to career possibilities. Thus, they take fewer risks with regard to career development. During the follow-up videotaping sessions more women referred to part-time employment than did men and reported that they worked longer hours for less remuneration. Although more research needs to be done on this topic, it is possible that in striving to be selfsufficient, women make more present-oriented decisions than do men, thereby reducing opportunities to persist toward long-term goals. It is also probable that more of the women students have more immediate financial pressures than do the men because they earn less.

Also of interest is the significance of siblings, teachers, and counsellors, but not of parents or parental education. Is it possible that parents, even affluent parents such as those represented in the demographics of this study, are not having substantial conversations with their sons and daughters about careers? Perhaps parents are taking for granted that their sons and daughters understand how they themselves earn a living. Some of the students in the follow-up group sessions could not discuss their parents' careers in any great depth because they apparently did not know what types of tasks and skills were involved. In the questionnaire, $63 \%$ of the students reported they had never talked with a chemist except for teachers and professors. Perhaps young people struggle with transition-related issues because, although they know school and part-time work environments well, they are naive about employment possibilities.

With regard to the transition to university from high school, gender differences were not statistically significant, although more males than females thought "there was considerable overlap" in the content of the two levels of chemistry courses. However, during the videotaped sessions, women more frequently expressed their concerns than did men. Generally, these concerns related to transition issues ("My first semester was a bit of a mess, but I think it was just a matter of getting used to it - taking five courses instead of three") or resources ("I had a guy take a reserve book right out of my hand"). With men the concern was more frequently career-related ("I've made about $\$ 200$ worth of phone calls to pharmaceutical companies."). On one topic, however, both women and men students were united: Mathematics is the most difficult course 
they have taken at university, the course on which they spent the most time, and the course they most frequently dropped. By doing so, they recognized they had lost a necessary prerequisite for a science or science-related career ("I need a 3.5 in math to get my B.Sc. and enter education.") These issues had not been probed in the questionnaire and suggest that meta-curricular concerns are important influences upon students' decision-making.

Differences with regard to the learning environment appear to substantiate previous research about the preference of women for interpersonal interaction (Gilbert \& Pomfret, 1991; Tobias, 1990). The reported preference by women for the laboratory environment may be related to the small group situation, and the possibilities of interacting with other people when learning new material. However, during laboratory visits, the faculty observer was impressed by the overall lack of interaction between students as they worked on their experiments. The little interaction that did occur took place around a piece of equipment used by everyone. Only three students, all women, called each other by name. Also, differences between women and men with regard to hands-on learning and visualization skills may contribute toward the differences in preferences for new classroom materials and evaluations. Finally, it may be that the lack of confidence many women seem to have regarding science courses is reflected in the time spent studying the material. In combination, perhaps these differences contribute to perceptions of a chilly climate in which to learn chemistry with women experiencing more alienation than men.

Concerns about relationships and achievement are more an aspect of firstyear women's lives than they are an aspect of first-year men's lives and so women utilize university support services more. By contrast, young men use campus recreation and computing services more, developing skills that contribute to positive attitudes of self-esteem, competence, and employability. Once again the significant differences in these concerns suggest that differing strategies are required if young women are to be retained in science and prepared to succeed in alternative careers. Beyond the retention policy issue is the larger question of how to make the university experience an environment which fosters the development of more humane people. Is it possible that young men need to be encouraged to develop better relationship skills while young women need to participate in physical activities that develop confidence?

Student perceptions of their abilities differed slightly from those of Gilbert \& Pomfret (1991), perhaps because the focus in this study was upon chemistry students in a commuter university. If young women think they have both poor reasoning abilities and problem-solving skills and they see that their grades drop upon entrance to university, the grade drop may appear to confirm their 
negative self-image. As a result they spend more hours studying and worry more about their ability to do university level work and they may not persist with courses in which they have difficulty. Visualization skills are important to scientists, and it is possible that many women's spatial abilities are less welldeveloped than are men's; thus, their ability to visualize three-dimensional models of chemical compounds may not be as acute. Possibly, as one student stated during the taped small group sessions, "I think there are two kinds of students in sciences. Some want to see the whole picture and then some want to see the details, and both are valid ways of learning but how can you teach the two kinds?" Given that more women work part-time than do men when at university and often carry more off-campus responsibilities, it is not surprising that they rank themselves highly in planning and organizing and in time management. Finally, differences between students enrolled in residential and commuter universities should be explored further as these data suggest the populations are not identical with regard to issues such as friendships, part-time work, and participation in campus activities.

Differences between Einsiedel's (1990) adult respondents and this student population with regard to science literacy appear less striking than the overall poor responses in both studies. With regard to the student sample, the variances in responses may be based less on a difference in knowledge about the content than on a reflection of differences between males and females with regard to admitting ignorance, attempting to answer questions, and expressing interest in biology versus physics. The videotaped comments provide some indication of why these students may have answered so poorly. Students stated they knew little about some professors' research and were surprised to read a name in a publication. The women had few role models: "They're needed to help girls relate to it better; maybe they need a different kind of encouragement," said one student.

Clearly, there is a problem with regard to students' understanding of science culture. Although students have acquired knowledge about chemistry courses, they seem to know a great deal less about chemistry itself and the applications of this discipline of knowledge. Both Einsiedel's study and this one indicate that Canadians generally, including university science students, do not appear to know much about their country's achievements in science or about the scientists who were the achievers. The implications are disturbing. In this area, gender differences appear to be less significant than the lack of understanding about how scientific knowledge is generated.

With regard to future destinations and possible linkages between education and employment, the young women students apparently recognize that their career paths may be affected by family responsibilities and many understand the 
advantages of cooperative education and volunteer experiences. These results are consistent with those found in the literature (Donaldson, 1990; Samuels, 1989) and reflect current realities. As undergraduate students they work parttime for less remuneration than do most of their male peers. Young women sometimes work because the responsibility enhances self-esteem. "I enjoy my job. At school, I'm nobody, but at work, I'm that first person who meets everyone. It's great," commented one who thought the course was interesting, but who accepted employment as a restaurant hostess during the semester.

Both young men and young women, however, may be uncertain about ultimate destinations. Most of these students will earn a credential, but they may not have a clear career goal or they may be uncertain of their ability to attain it. Students in the follow-up videotaped small group sessions suggested that the university has organized "weeder" courses to eliminate poor students (chemistry was one of them). Claimed one reentry female student, "When the professor says they are deliberately trying to drop the marks down, you have to question what's going on behind the scenes."

Subsequent to the Phase One data collection, increases in enrollment statistics are encouraging, very likely influenced by proactive strategies. Among the changes implemented by the Department of Chemistry since the project was initiated are such policies as a First-Year Steering Committee which is implementing curricula changes, the placement of all three women faculty into the first-year course (one of whom is department head) to provide role models, promotional activities such as an award winning poster, and faculty support for a Women in Science and Engineering (WISE) peer support group. These efforts have resulted in curricula revisions especially in the wet and computer laboratories, small group activities in the wet labs and in tutorials, written questions in the final examinations, expansion of cooperative education, increased liaison with the kindergartengrade 12 system, and presentations to other faculties. .Phase Two of the research project discussed here should capture some of the results of such initiatives when data from a sample of the 1993 first-year chemistry class are compared to the 1991 one. Also, a small sample of the Phase One students was tracked. Obvious short-term results of these efforts are the immediate larger enrollment of women in more advanced chemistry courses as evidenced by the subsequent registration of women who were in the Phase One sample, changes in the chemistry curricula that benefit both male and female students, and increasing commitment by the faculty toward new pedagogical initiatives. 


\section{Conclusions and Implications}

While intervention strategies are apparently retaining more women in science beyond the first-year of university, gender differences appear to signal more lifestyle diversification than mere course selection or academic achievement. As undergraduates, women were more confident of their abilities to manage time and to plan and organize their affairs. Perhaps this confidence results from an already more fragmented lifestyle. They have a strong desire to be self-sufficient, although their part-time earnings are lower than those of their male counterparts. More so than men, they recognize the usefulness of part-time work experience, cooperative education, and volunteerism in developing careers. Given that these commuter students usually come from relatively socioeconomically advantaged families, questions arise about the influence of consumer lifestyles upon long-term goals. These transition patterns into and during the first-year of university suggest that the career paths and lifestyles of women and men begin to differentiate between them in ways much more profound than course selection. Thus, the educational outcomes may be quite different.

Intervention strategies by the faculty in the Department of Chemistry appear to have had positive short-term effects. Utilizing data from this study, the First-Year Steering Committee has made curricula and evaluation changes, facilitated promotional and peer support groups, and encouraged female faculty to act as role models for entering students. Although the number of women students from this cohort persisting in senior chemistry courses has increased from that of previous years, as these students proceed through their undergraduate programmes there will undoubtedly be further attrition. With regard to longterm consequences, women students are enrolling in increasing numbers in chemistry, in other sciences, and in engineering, but the numbers of women and men are not yet equitable.

It seems apparent that the chilly climate of science studies can be improved to the advantage of everyone involved. Furthermore, if women and men establish differing priorities with regard to solving scientific problems, then it is reasonable to speculate about how society might be changed if more women were to become scientists. Finally, more research is needed so that postsecondary policies, especially during a period of restraint, are informed by a dialogue as sustained as any within the individual disciplines that comprise the university community. 


\section{Acknowledgements:}

The authors appreciate the comments of several reviewers, some anonymous, whose suggestions have made this article more readable. In addition, the comments of Dr. C. Violato and Dr. A. Marini regarding statistical analysis and presentation of results were invaluable.

\section{References}

Chenard, P. (1988). L' interruption des études à l'université du Québec. Volet I: la problématique. Québec: Université du Québec.

Corman, J., Barr, L., \& Caputo, T. (1992). Unpacking attrition: A change of emphasis. The Canadian Journal of Higher Education, 22(3), 14-27.

Donaldson, E. L. (1990). Links between education and employment: What is the educator's responsibility? Journal of Educational Administration and Foundations, $5(2), 52-62$.

Donaldson, E. L. (1992). Patterns and profiles in the transition from school to work. Journal of Educational Administration and Foundations, 7(1), 30-47.

Einsiedel, E. A. (1990). Scientific literacy: A survey of adult Canadians (SSHRC Grant Report). Calgary: University of Calgary.

Etcheverry, E. J., Clifton, R. A., \& Roberts L. W. (1993). Time use and education attainment: A study of undergraduate students. The Canadian Journal of Higher Education, 23(3), 1-17.

Evers, F. T., Rush, J. C., \& Krmpotic, J. A. (June,1991). The role of employersponsored training in the skill development process of university graduates. Paper presented at the Canadian Society for The Study of Higher Education, Kingston, ON.

Gilbert, S. N. \& Pomfret, A. (1991). Gender tracking in university programs, final report. Industry, Science and Technology Canada, (\#67GUS-9-0378).

Gilligan, C., Lyons, N., \& Hanmer, T. (Eds.). (1990). The relational worlds of adolescent girls at Emma Willard School. Cambridge, MA: Harvard University Press.

Gomme I,. Hall, M. P., \& Murphy, T. J.. (1993). In the shadow of the tower: The view of the undergraduate experience. The Canadian Journal of Higher Education, 23(3), 18-35.

Mandell, N., \& Crysdale, S. (1993). Gender tracks: Male-female perceptions of homeschool-work transitions. In P. Anisef \& P. Axelrod (Eds.), Transitions, (pp. 21-43). Toronto: Thompson Educational Publishing Inc.

McKeown, B., MacDonnell, A., \& Bowman, C. (1993). The point of view of the student in attrition research. The Canadian Journal of Higher Education, 23(2), 65-85.

Samuels, B. A. (1989). Women, science and engineering: Can co-op assist? Calgary: University of Calgary.

Streit, U., \& Tanguay, Y. (1994). Professional achievement, personality characteristics and professional women's self-esteem. In J. Gallivan, S. Crozier, V. Lalande (Eds.), Women, girls, \& achievement, (pp. 63-76). North York, ON: Captus University Press.

Tinto, V. (1987). Leaving college. Rethinking the causes and cures of student attrition. Chicago: University of Chicago Press. 
Tobias, S. (1990). They're not dumb, they're different: Stalking the second tier. Tucson: Arizona Research Corporation.

University of Western Ontario. (1991). The Chilly Climate.(videotape) London, ON: University of Western Ontario.

Williams, D. (1990). Is the post-secondary classroom a chilly one for women? The Canadian Journal of Higher Education 20(3), 29-42. 